\title{
Professional responsibility in the aspect of road transport education
}

\author{
Galina V. Bukalova ${ }^{1 *}$ and Alexander N. Novikov ${ }^{1}$ \\ ${ }^{1}$ Orel state university named after I.S. Turgenev, 302026, Orel, 95, Komsomolskaya str., Russia
}

\begin{abstract}
The modern functioning of the technical sphere of production is due to the development of post-industrial society. In the context of postindustrial development, the inevitable transition to free and responsible activity of individuals is predicted. In the concept of professional responsibility inherent in the post-industrial society, the moral and ethical sphere of engineering education of the motor transport profile is significantly highlighted. Based on the results of a multi-panel study conducted at the Department of Machine Service and Repair of Orel State University, a high level of actual significance of the competencies of university graduates, reflecting their readiness for professional responsibility, was established. In this regard, a scientific and pedagogical problem, little emphasized before, is formulated-the formation of a moral and ethical competence profile in the course of the educational process. The article presents a theoretical consideration of professional responsibility as a significant mechanism for regulating engineering activities in the aspect of the provisions of metaethics. The article analyzes the didactic characteristics of educational activities aimed at mastering the provisions of professional responsibility of engineering and technical workers of the motor transport complex by university students.
\end{abstract}

\section{Introduction}

Modern conditions of functioning of engineering education dictate the need to expand the interpretation of the subject of engineering pedagogy, proposed by its founder Adolf Melecinek: "Everything that is aimed at improving the teaching of technical disciplines". The development of a post-industrial society actualizes the integrity of the pedagogical system of training engineering and technical workforce, including the formation of professional responsibility based on engineering ethics. As a system of declared principles, values and rules, engineering ethics is designed to stimulate the self-awareness of employees and set guidelines for productive work behavior. This significantly emphasizes the professional responsibility of the performers of the work. In view of this, the formation of readiness for professional responsibility of graduates of the university of engineering profile is being updated [1, 2, 3].

In the modern conditions of the development of a post-industrial society in the field of technical production, centralization is replaced by autonomy and the associated

*Corresponding author: 57orleya@gmail.com. 
responsibility $[4,5]$. In a post-industrial society, individualization is recognized as the main characteristic of human capital $[6,7,8]$. The inevitable transition to free and responsible activity of individuals is proved by the well-known researcher in the field of sociology and political science D. Bell [4]. The concept of individualization inherent in the post-industrial society serves as the basis for making certain changes in the performance-target sphere of engineering education of the motor transport profile.

In the Polytechnic Institute of the Federal State University of Higher Education "Oryol State University" named after I. S. Turgenev, a study was carried out to determine the level of actual significance of the graduate's competencies declared by the university in the field of training "Operation of transport and technological machines and complexes"[9]. The competence-based approach formed the methodological basis of the study. The research method is a questionnaire in the form of an expert survey. The object of the study is the actual significance of educational goals in the form of the competencies of the engineering and technical personnel of the car service company.

\section{The main part}

To determine the level of actual significance of the university graduate's competencies, the respondents used a quantitative approach. A 100-point rating scale was used. The number of car service companies in the Orel region-official dealers of car manufacturers-served as the basis for determining the volume of the general sample of the study. The generation of respondents was made up of managers and specialists of these car service companies, as well as students and undergraduates of the university studying in the direction of "Operation of transport and technological machines and complexes". Based on the results of the study, it was found that the highest level of recognition by the respondentsproduction workers was determined for the actual significance of the competencies of the moral and ethical profile. The weighted average ratings of respondents of the actual significance of the competencies of the moral and ethical profile of an engineering and technical employee of an auto-service enterprise are presented in the table 1.

Table 1. The level of actual significance of the competencies of the engineering and technical personnel of the car service company.

\begin{tabular}{|c|c|c|}
\hline \multicolumn{1}{|c|}{$\begin{array}{c}\text { Competencies of } \\
\text { engineering and technical personnel }\end{array}$} & $\begin{array}{c}\text { Evaluation } \\
\text { by production } \\
\text { specialists-brooms } \\
\text { (points) }\end{array}$ & $\begin{array}{c}\text { Assessment } \\
\text { by university } \\
\text { students } \\
\text { (points) }\end{array}$ \\
\hline $\begin{array}{c}\text { The ability to work in a team, tolerant of } \\
\text { social and cultural differences. }\end{array}$ & 96,82 & 57,87 \\
\hline $\begin{array}{l}\text { Willingness to follow moral and ethical } \\
\text { standards. }\end{array}$ & 96,92 & 66,45 \\
\hline $\begin{array}{l}\text { Knowledge of the types of professional } \\
\text { responsibility in the aspect of moral and ethical } \\
\text { standards. }\end{array}$ & 93,85 & 55,64 \\
\hline
\end{tabular}

A significant discrepancy in the assessment of the significance of the competencies of the moral and ethical profile directly indicates the presence of an important pedagogical problem: purposeful changes in the value-semantic position of students in relation to the development of competencies of a moral and ethical nature.

The peculiarity of the motor transport education system is that the formation of the goals of its functioning takes place outside of this system. The production activity of the 
motor transport complex and the socio-economic trends in the development of society as a whole determine the educational goals of professional specialized training $[2,10,11]$. Because of this, the problem of the validity of educational goals (competencies of a university graduate) is one of the most significant problems in the field of engineering motor transport education. The revealed significance of the development of moral and ethical competencies by university graduates actualizes the theoretical consideration of professional responsibility as a significant mechanism for regulating engineering activities.

Professional responsibility in the general scientific understanding is represented as the ability of an employee to perform their professional duties, aware of their consequences. [12-15]. At the same time, its objective and subjective sides are distinguished [3]:

- the direct relationship between the result of the activity and its consequences reflects the objective side of professional responsibility;

- the employee's understanding of their involvement in the consequences of the activity is the subjective side of professional responsibility.

At the same time, at the personal level, the subjective side of professional responsibility can manifest itself as:

- readiness for risk, and in the field of car service production, only an acceptable level of risk is assumed;

- an understanding of the inevitable "risk fee", in case of exceeding the acceptable level of risk.

In industrial engineering, it is generally accepted that the measure of professional responsibility of an engineering and technical employee depends on the level of independence and the scale of technical and technological, managerial decisions taken; the significance of their possible negative consequences; the authority, professional status of the employee [16-18]. The administrative powers of an engineering and technical employee formally determine their professional responsibility. It should be noted that in the real production process, the social significance of professional responsibility and the personal perception of it as such by the employee may not coincide. However, a certain and specific awareness of possible negative consequences determines the performance of production activities in accordance with the requirements of professional responsibility.

In the scientific psychological and pedagogical sphere, the discussion of the phenomenon of professional responsibility is carried out in the context of professional ethics [4, 19-22]. The justified formation of educational goals of a moral and ethical nature in the field of motor transport education involves the development of a complex of pedagogical and socio-philosophical ideas that are primary in relation to practical pedagogical activity. As a methodological basis for solving the pedagogical problem under consideration, it seems appropriate to use the provisions of metaethics - areas of analytical and philosophical methodology [23]. Metaethics is a part of logical positivism and is known as a field of study of methodological problems of ethics. In metaethics, the elements of morality are divided into prescriptive (unconditionally valuable) and descriptive (provable with the help of certain arguments) [24]. Each competence, as an educational goal, of a moral and ethical nature, is essentially (in terms of metaethics) a normative and ethical conclusion.

Therefore, in the totality of the competencies of the moral and ethical group, it is necessary to distinguish the competencies of a prescriptive and descriptive nature. The identification of the competencies of these groups is necessary to ensure the optimal choice of pedagogical technologies for their formation. Thus, the application of the presented conceptual and theoretical position of metaethics regarding prescriptive competencies leads to a rather unexpected conclusion. The pedagogical task of mastering these competencies is only to present them to the students as positive ethical guidelines for labor behavior. The rationale for this is the thesis of the famous researcher in the field of ethics L. V. 
Maximov, who proved that moral values of a prescriptive nature "... should be considered as 'facts' or realities of human life that allow for a causal explanation, but not a logical justification" [23, p. 51]. In the aspect of the provisions of metaethics, the creation of this educational condition is sufficient for the student to become a carrier of generally recognized ethical values. The characteristic feature of competencies (educational standards), considered from the position of the non-cognitive approach, is that they reflect the generally valid principles of morality., as if answering the question about the content of the duty of an engineering and technical employee is absolutely mandatory. Educational goals that declare moral values of a prescriptive nature represent the desired moral position of an engineering and technical employee.

The competencies of a university graduate of an ethical nature, reflecting the specific requirements of the specialized field of production, should be presented from the position of the cognitive approach implemented in the concept of descriptive ethics [22]. Consequently, the formation of students ' ethical competencies of this type can be carried out using descriptive and explanatory learning technology, as well as contextual learning technology. In view of the fact that in accordance with the conceptual provisions of descriptive ethics, the development of these competencies by students requires an explanation of the value positions of the performer of engineering activities and their actual justification. For the engineering and technical personnel of the motor transport industry, a wide variety of types of responsibility is characteristic, due to technical regulations, working instructions, contractual relations with customers, etc.And these elements of professional responsibility cannot be attributed directly to moral responsibility. In the scientific field of professional ethics, these types of responsibility are referred to as "ethically neutral or extra-moral" (the terms of G. Lenk) $[20,13]$. In the conditions of the production process of the technical profile, the extra-moral duty must necessarily be included in the structural omposition of the professional responsibility of the engineer [17, 21, 25].

The modern sphere of motor transport services is characterized by a pronounced valueoriented, entrepreneurial nature. At the same time, production activities are necessarily focused on efficiency and profitability $[11,22,26]$. The achievement of these values in the production process is part of the professional responsibility of an engineering and technical employee, as well as in the future and a graduate of a university of motor transport profile. However, the well-being of people-consumers of motor transport services-is an absolute, generally accepted value, which determines the moral duty of an engineer of any profile. This situation makes it possible to form a conflict between the moral and extra-moral responsibility of the engineering and technical personnel of the motor transport enterprise. In view of this, for the development of professional responsibility by students of the motor transport profile, it is necessary to create educational conditions aimed at forming their readiness to unconditionally perceive the priority of moral responsibility, even if this causes a decrease in production and economic indicators of activity.

When forming the professional responsibility of students of the motor transport profile, it is necessary to take into account the ethical problem of the distribution of professional responsibility between the performers of the work inherent in the motor transport production process. It is known that modern labor processes in the auto-service sector are implemented by groups of employees. At the same time, in the production activity of the motor transport profile, it is often difficult to identify the result of the work of an individual employee in the total result of the work of the working group of which he is a member [17]. The consequence of this is the difficulty of identifying the personal responsibility of the employee. As a result, objective conditions are created for the emergence of two ethical problems of motor transport production activities that belong to the field of professional responsibility. The first problem is the difficulty of identifying 
professional responsibility within the working group. The second problem arises due to the lack of direct labor interaction between employees of partner enterprises implementing an interconnected production process.

The presence of these specific ethical problems in the practice of engineering and motor transport activities is the basis for the development of university students ' competencies that reflect their readiness for professional responsibility, represented by the external, corporate responsibility of the working group and the enterprise as a whole. In this regard, in the educational process, it is necessary to emphasize the social aspect of autoservice activities, which combines the professional responsibility of an individual employee and collective, corporate responsibility. Based on the conceptual provisions of professional ethics, it should be noted that the moral responsibility of the working team is possible provided that it is not assigned to the team as a whole, but to the employees - members of this team. Considering that professional responsibility is a component of the employee's personality [11]. It is also important to bring to the attention of students of motor transport training the concept that the degree of professional responsibility cannot be reduced due to an increase in the number of responsible working groups. Thus, it is possible to form students ' understanding of the inevitability of future personal involvement in collective professional responsibility, different from the individual responsibility of the employee.

The professional responsibility of an employee of the motor transport sector of production is associated not only with ethical problems that have an anthropocentric character. The professional responsibility of the engineer also includes the state of the environmental conditions of the environment. The functioning of enterprises in the motor transport sector of production can have a significant harmful impact on the environment. Moreover, the vast ecological system of the whole region can suffer from such an impact. The problem of the negative impact of the sphere of production on the ecological state of the environment can be attributed to ethical problems due to its possibly uncontrolled nature. Often, only the professional responsibility of the performers of industrial road transport activities can serve as a guarantee of preserving the ecological well-being of the region.

In the general scientific understanding, human ecology is a branch of ecology as a science. Human ecology considers the conditions of interaction between humans and the environment. The result of production is an integral element of the environment. Professional responsibility is an important moral imperative that determines the environmental friendliness of the result of road transport activities. Accordingly, the pedagogical problem of forming the readiness of students of the motor transport profile to meet the requirements of professional responsibility in relation to the environmental safety of production activities is revealed.

\section{Conclusion}

The presence of the presented specific ethical problems in the practice of engineering activities of the motor transport profile is the basis for the development of university students ' competencies that reflect their readiness for professional responsibility, represented by the external, corporate responsibility of the working group and the enterprise as a whole. In this regard, in the educational process of the university, it is necessary to emphasize the social aspect of auto-service activities, which combines the professional responsibility of an individual employee and collective, corporate responsibility.

Documentation actually significant readiness of a graduate of a motor transport university for professional responsibility in the process of future production activities is necessary in the form of a normative establishment of appropriate educational goals (educational rationing). The presentation of educational goals of this type is possible in the 
form of a declaration by the university of the relevant competencies of the graduate of the university, which are part of the educational training program in a specific professional direction.

In the educational process of an engineering university, it is advisable to present the following signs of professional responsibility of an engineering and technical employee:

- compliance with the requirement of conscientious performance of labor activity by an employee who fully possesses professional competence corresponding to the profile of industrial activity;

- evaluation of production activities in material and moral and ethical aspects;

- the application of sanctions to compensate for the damage caused as a result of professional activity.

Engineering pedagogy as a field of scientific research is characterized by the orientation of the scientific attitude to the consideration of educational reality in the form of an object. Highlighting the readiness for professional responsibility of a graduate of a motor transport university as such an object, it is advisable to turn to engineering pedagogy as a practical activity of a teacher of a higher technical school aimed at the formation of this specific group of competencies.

\section{References}

1. T.N. Persikova, Corporate culture, (Logo, 2011).

2. O.V. Perfil`eva, University and region: towards the realization of the third function, Bulletin of international organizations, v.1, pp. 133-144, (2011).

3. C. Price, \& A. Whiteley, Corporate Culture and Employee Identity: Cooption or Commitment through Contestation? Journal of Change Management, v.2 (14), pp. 210-235 (2014).

4. D. Bell, The coming post-industrial society. Experience of social forecasting, (Akademiya, 2004).

5. A. Kosyakov, U. Svit, S. Sejmur, S. Bimer, System engineering. Principles and practice (DMK-Press, 2014).

6. L.L. Bucciarelli, Ethics and Engineering Education, European Journal of Engineering Education, v. 2(33), 2008. pp. 141-149.

7. J. Dempsey, Moral Responsibility, Shared Values, and Corporate Culture, Business Ethics Quarterly, v. 3(25), pp. 319-340, (2015).

8. K. Illes, C.Vogell, Corporate values from a personal perspective, Social Responsibility Journal, v.14, pp. 351-367, (2018).

9. G.V. Bukalova, A.N. Novikov, Updating of educational standards-the basis for determining changes in the content of engineering education, The world of transport and technological machines, v. 3 (62), pp. 129-160, (2018).

10. L.N. Bannikova, L.N Boronina, I.I. Sholina, Experience in modeling new approaches and tools to assess regional needs for a new generation of engineering personnel, Engineering education, v.19, pp. 122-128, (2016).

11. M. Adam, K. Miller, Situated Regional University Incubation: A Multi-Level Stakeholder Perspective, Technovation. v. 50, pp.69-78, (2016).

12. E. Agaczci, The moral dimension of science and technology (Moscow philosophical Foundation, 1998).

13. X. Lenk, Reflections on modern technology (Aspect-Press, 1996).

14. J. Beckmann, Vom Nutzen und von den Grenzen von Ingenieur-Codices, Philosophie und Technik, S. 191-201, (2000).

15. S. Lester, Professional standards, competence and capability, Higher Education, Skills and Work-based Learning, v. 4, pp. 31-43, (2014). 
16. N.G Bagdasar`yan, V.G., Goroxov, A.P. Nazaretyan, History, philosophy and methodology of science and technology, (Jurayt Publishing house, 2014).

17. N. Yu. Postalyuk, The mechanisms of translation of the qualification requirements of the labour market in vocational education and training. Professional education in Russia and abroad, v. 3(15), pp. 37-40, (2014).

18. G. Jonas, Principle of responsibility. Experience ethics for technological civilization, (Iris Press, 2004).

19. Yu.V. Gasheva, Engineering ethics: problems of competence formation and assessment, Higher education in Russia, v.6, pp. 85-93, (2014).

20. X. Lenk, Problems of responsibility in ethics Economics and technology. Question of philosophy, v. 1, pp. 30-42, (1998).

21. R.S. Safin, E.A. Korchagin, Methods of designing the goals and content of the professional educational program in a technical University, Actual problems of Humanities and social and economic Sciences, v. 10(11), pp. 61-66, (2017).

22. A.I. Chuchalin, Modernization of the economy and improving the quality of engineering education, Almamater, v.11, pp. 12- 19, (2011).

23. L.V. Maksimov, An essay on modern metaethics. Problem of philosophy, v.10, pp. 39-54, (1998).

24. G.V. Bukalova, Conceptual grounds for rationing the result of vocational education of technical profile, (FBGOU HPE "State University- UNPK", 2014).

25. V. E. Gimpelson, R. I. Kapelyushnikov, Russian worker: education, profession, qualification, (National research University Higher school of Economics. Publishing house of the Higher school of Economics, 2011).

26. D. Bravenboer, S. Lester, Towards an integrated approach to the recognition of professional competence and academic learning, Education + Training, v. 58, pp. 409-421, (2016). 